\title{
Review
}

\section{BCL-2 family: integrating stress responses at the ER to control cell demise}

\author{
Philippe Pihán ${ }^{1,2,3}$, Amado Carreras-Sureda ${ }^{1,2,3}$ and Claudio Hetz ${ }^{\star 1,2,3,4,5}$
}

In the last decade, the endoplasmic reticulum (ER) has emerged as a central organelle regulating the core mitochondrial apoptosis pathway. At the ER membrane, a variety of stress signals are integrated toward determining cell fate, involving a complex cross talk between key homeostatic pathways including the unfolded protein response, autophagy, calcium signaling and mitochondrial bioenergetics. In this context, key regulators of cell death of the BCL-2 and TMBIM/BI-1 family of proteins have relevant functions as stress rheostats mediated by the formation of distinct protein complexes that regulate the switch between adaptive and proapoptotic phases under stress. Here, we overview recent advances on our molecular understanding of how the apoptotic machinery integrates stress signals toward cell fate decisions upstream of the mitochondrial gateway of death.

Cell Death and Differentiation (2017) 24, 1478-1487; doi:10.1038/cdd.2017.82; published online 16 June 2017

\section{Facts}

- Mitochondrial outer membrane permeabilization (MOMP) is a critical check point in the control of apoptosis. MOMP is regulated by a balance between pro- and anti-apoptotic proteins of the BCL-2 family.

- Under sustained endoplasmic reticulum (ER) stress conditions, the unfolded protein response (UPR) triggers apoptosis in part through the transcriptional and posttranslational regulation of proapoptotic $\mathrm{BH} 3$-only proteins.

- Several proteins of the BCL-2 family localize to the ER membrane, impacting mitochondrial biology at a distance through the regulation of $I P_{3} R$-dependent calcium release.

- BAX and BAK homo-oligomerize at the ER membrane, leading to its permeabilization and the release of ER luminal proteins to the cytosol.

- The BCL-2 protein family operates as a core to integrate stress signaling networks, regulating cell death, calcium homeostasis, the UPR and autophagy.

\section{Open Questions}

- How does ER permeabilization lead to cell death?

- What is the functional relationship between proteins of the BCL-2 and TMBIM families in the regulation of cell death?

- Are TMBIM proteins ion channels? Is the channel activity relevant for their apoptotic regulatory functions?

- Do BCL-2-related proteins modulate the switch between proadaptive to proapoptotic ER stress responses?

Apoptosis is a highly conserved and tightly regulated process to eliminate damaged or unrequired cells. Alterations in the control of apoptosis are at the root of a large array of human diseases, including cancer, neurodegenerative diseases and autoimmunity, among others. ${ }^{1,2}$ Cell death driven by apoptosis is characterized by a specific sequence of morphological changes, ${ }^{3}$ starting with cell shrinkage, chromatin and organelle fragmentation, and loss of cell-to-cell and cell-to-matrix interactions, followed by the disintegration of the cell into apoptotic bodies and their subsequent engulfment and degradation by phagocytic cells. ${ }^{4}$ These phenotypic changes are orchestrated by specialized cysteine-aspartic proteases of the caspase family, which cleave and inactivate more than 400 intracellular protein targets, catalyzing the controlled demolition of the cell. ${ }^{4}$

In vertebrates, apoptosis proceeds through two distinct but interrelated signaling cascades defined as the intrinsic and extrinsic cell death pathways. In the extrinsic pathway, the engagement of membrane receptors (i.e., TNF $a$ or Fas receptors) results in the recruitment of distinct adapter proteins and activation of initiator caspase (i.e., caspase-8), which in turn cleaves and activates executioner caspases (i.e., caspase-3 and -7). The intrinsic pathway of apoptosis is initiated in response to a myriad of intracellular physiological or cytotoxic stimuli, such as DNA damage, viral infections and endoplasmic reticulum (ER) stress, among others. ${ }^{5}$ Even though these perturbations can be initiated at different cell sites, most of the signaling pathways triggered by irreversible damage converge at the mitochondria outer membrane, where they trigger its permeabilization. ${ }^{5}$

Mitochondria outer membrane permeabilization (MOMP) is considered the point of no return of the intrinsic apoptosis pathway and thus, a critical check point for cell death control. MOMP results in the release of cytochrome $c$ and many other proapoptotic factors, leading to the formation of the

${ }^{1}$ Faculty of Medicine, Biomedical Neuroscience Institute, University of Chile, Santiago, Chile; ${ }^{2}$ Program of Cellular and Molecular Biology, Institute of Biomedical Sciences, University of Chile, Santiago, Chile; ${ }^{3}$ Faculty of Medicine, Center for Geroscience, Brain Health and Metabolism, University of Chile, Santiago, Chile; ${ }^{4}$ Buck Institute for Research on Aging, Novato, CA 94945, USA and ${ }^{5}$ Department of Immunology and Infectious Diseases, Harvard School of Public Health, Boston MA 02115, USA

${ }^{*}$ Corresponding author: C Hetz, Faculty of Medicine, Biomedical Neuroscience Institute, University of Chile. Av. Independencia 1027 Bloque B P.O.BOX, Santiago 70086, Chile. Tel: +56 229786506; Fax: 56 29786871; E-mail: chetz@med.uchile.cl or chetz@ hsph.harvard.edu

Received 10.1.17; revised 24.3.17; accepted 11.4.17; Edited by G Melino; published online 16.6.17 
a

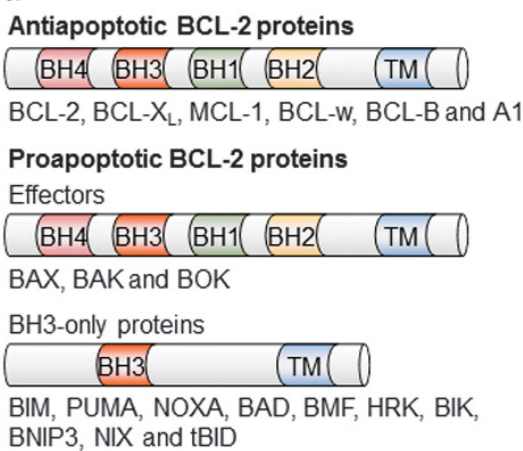

b

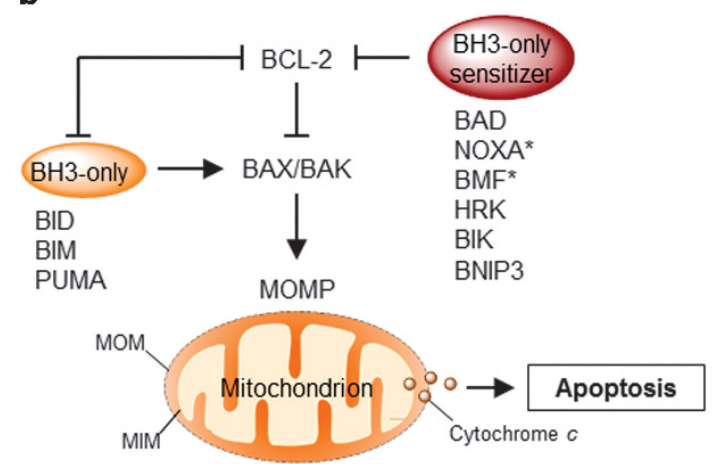

Figure 1 Regulation of apoptosis by the BCL-2 family. (a) The BCL-2 family of proteins is divided into three groups based on their functional role in the regulation of apoptosis and the number of BCL-2 homology $(\mathrm{BH})$ domains they bear. (b) The BCL-2 proteins regulate the permeabilization of the mitochondrial outer membrane (MOMP) and apoptosis through a specific network of heterodimeric interactions. In one model, termed the direct activation model, a subset of BH3-only proteins directly engages and activates BAX or BAK leading to MOMP. Prosurvival BCL-2 proteins suppress apoptosis through their interaction with and sequestration of these 'activator' BH3-only proteins. Other BH3-only proteins - denominated 'sensitizers' - may competitively interact with prosurvival proteins, releasing activator BH3-only proteins. In the neutralization model, constitutively active BAX and BAK are kept in check by prosurvival BCL-2 proteins. Upon activation, BH3-only proteins interact with and 'neutralize' prosurvival BCL-2 proteins, releasing BAX and $B A K$ and engaging MOMP. It is likely that aspect of both models contribute to the regulation of apoptosis under physiological conditions. BAD, BCL-2 antagonist of cell death; BAK, BCL-2 antagonist or killer; BAX, BCL-2-associated X protein; BID, BH3-interacting domain death agonist; BIK, BCL-2-interacting killer; BIM, BCL-2-interacting mediator of cell death; BMF, BCL-2-modifying factor; BNIP3, BCL-2 and adenovirus E1B $19 \mathrm{kDa}$ protein-interacting protein 3; HRK, harakiri; PUMA, p53-upregulated modulator of apoptosis; $\mathrm{TM}$, transmembrane. *NOXA and BMF have also been shown to exhibit direct activation function under certain circumstances

apoptosome followed by the activation of the caspase cascade. ${ }^{1,2}$ Given its central role in apoptosis, MOMP is tightly controlled by several positive and negative regulators, where we highlight the involvement of the B-cell lymphoma 2 (BCL-2) family of proteins. In mammals, the BCL-2 family is composed by at least 20 members, functionally grouped into anti- and proapoptotic proteins, and further subdivided according to the presence of up to four BCL-2 homology $(\mathrm{BH})$ domains $^{1,6}$ (Figure 1a). Anti-apoptotic proteins contain all four $\mathrm{BH}$ domains and include BCL-2 itself, BCL- $\mathrm{X}_{\mathrm{L}}, \mathrm{MCL}-1, \mathrm{BCL}-\mathrm{w}$ and $A 1$. Proapoptotic proteins are further subdivided into two groups: multidomain proteins $\mathrm{BAX}, \mathrm{BAK}$ and $\mathrm{BOK}$, also containing all four $\mathrm{BH}$ domains and 'BH3-only members' (i.e., BID, BIM, NOXA and BAD); evolutionary divergent proteins that only bear the $\mathrm{BH} 3$ domain operating as essential apoptosis inducers. ${ }^{1,6}$

The BCL-2 family may be viewed as a tripartite apoptotic switch, ${ }^{7}$ where BAX and BAK act as gatekeepers of MOMP (Figure 1b). Indeed, apoptosis signals trigger the translocation of BAX from the cytosol to the mitochondria, where it assembles into higher-order homo-oligomers that form a pore that permeabilize the mitochondrial outer membrane. ${ }^{7}$ BAX and BAK activation and oligomerization is engaged by upstream BH3-only proteins and antagonized by antiapoptotic BCL-2 family members; either by direct interaction or inhibition of BH3-only proteins (Figures $1 \mathrm{~b}$ and $4 \mathrm{a}$ ). Thus, the balance between anti- and proapoptotic proteins determines the survival or death of a cell. ${ }^{1,6}$ Although the primary place of action of the BCL-2 family is at the mitochondrial membrane, several members also localize to the ER in different proportions, where they can modulate the mitochondrial apoptosis pathway at a distance by several mechanisms. ${ }^{8}$ Indeed, in the last decade, the ER has emerged as a critical place of apoptosis control in response to a wide variety of stress stimuli. This review focuses on discussing the contribution of the BCL-2 family to various stress responses at the ER membrane and the consequences over the intrinsic cell death pathway.

\section{ER stress signaling and cell fate control}

The ER is the main organelle involved in protein folding and secretion where around a third of the total proteome is synthetized; in addition to operate as the central intracellular calcium store and a site of lipid synthesis. Several perturbations can result in ER stress, a cellular condition involving the accumulation of unfolded or misfolded proteins in its lumen. ${ }^{9}$ ER stress engages a complex and dynamic signaling network termed the unfolded protein response (UPR). The UPR operates as a global rheostat to determine cell fate under ER stress. The UPR initially signals to establish an adaptive program aimed at reestablishing ER proteostasis by increasing the folding capacity of the cell, reducing protein synthesis and enhancing the clearance of abnormally folded proteins and damaged organelles. ${ }^{10}$ If ER homeostasis cannot be restored, the UPR shifts its signaling toward a proapoptotic response to eliminate the damaged cell. ${ }^{11}$ Here we summarize key aspects of UPR signaling involved in cell survival and apoptosis control and how it relates to the BCL-2 family of proteins.

Prosurvival signaling. The UPR involves a complex signaling transduction pathway, initiated by at least three type of stress sensors or transducers localized to the ER membrane, including inositol-requiring enzyme 1 (IRE1)a, PKR-like endoplasmic reticulum kinase (PERK) and activating factor 6 (ATF6) $a .^{12}$ IRE1a is a bifunctional kinase and endoribonuclease enzyme representing the most conserved UPR signaling branch. Under ER stress, IRE1 $a$ becomes activated and mediates the expression of the transcription factor $\mathrm{X}$-box 


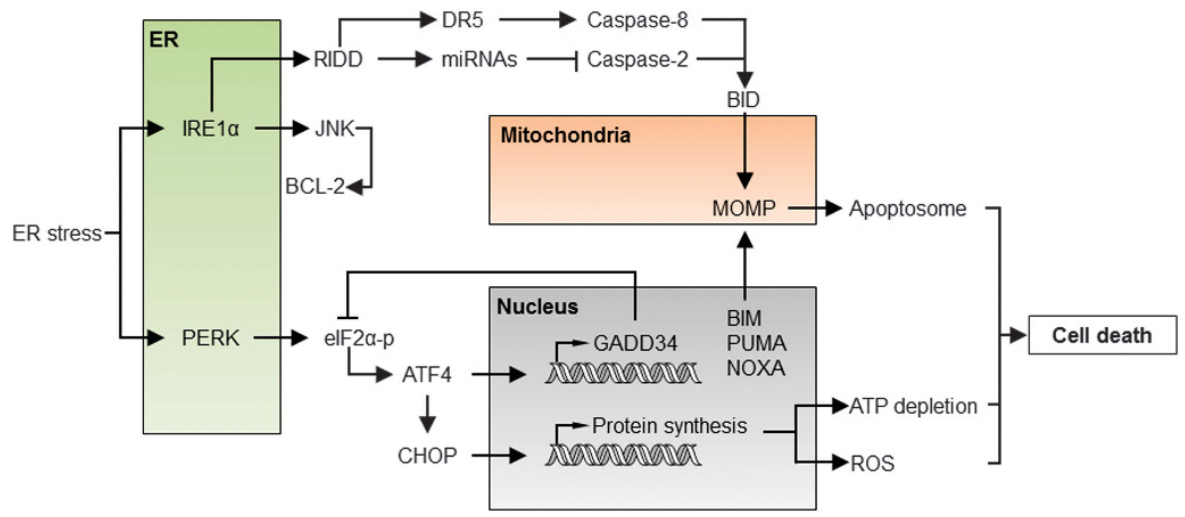

Figure 2 The apoptosis regulatory network under ER stress. Under acute or sustained ER stress, the UPR actively promotes apoptosis through the regulation of proapoptotic proteins of the BCL-2 family, increased proteotoxicity and ROS. IRE1 $\alpha$ activation engages the degradation of several ER-localized RNAs through RIDD, having a dual role in apoptosis regulation. Degradation of several inhibitory miRNAs leads to the activation of caspase-2, which in turn cleaves and activates the BH3-only protein BID triggering the mitochondrial pathway of apoptosis. Conversely, degradation of the DR5 mRNA results in the inhibition of caspase-8, repressing cell death. JNK is also activated downstream of IRE1 $\alpha$, inducing cell death through BCL-2 phosphorylation and inhibition. Activation of PERK leads to the phosphorylation of elF2 $\alpha$ and global protein synthesis arrest. Under these conditions, ATF4 is selectively translated and, together with CHOP, transcriptionally activates several BH3-only proteins, engaging the mitochondria. Moreover, the ATF4/CHOP complex resumes protein synthesis through the upregulation of the GADD34 phosphatase and other genes, leading to ATP depletion, ROS and finally cell death. ATF4, activating transcription factor 4; DR5, death receptor 5; GADD34, growth arrest and DNA damage-inducible protein 34; JNK, c-Jun N-terminal kinase; RIDD, regulated IRE1-dependent decay

binding protein 1 (XBP1), ${ }^{9}$ controlling genes involved in ER homeostasis maintenance. ${ }^{12}$ The RNase domain of IRE1a has additional substrates, degrading many RNAs through a process known as regulated IRE1-dependent decay (RIDD). ${ }^{13}$ Upon activation, PERK signaling blocks protein synthesis by phosphorylating the translation initiator factor elF2 $a$, reducing the overload of misfolded proteins inside the ER. elF2a phosphorylation allows the selective translation of ATF4, a transcription factor that transactivates genes related to protein folding, redox control and amino-acid metabolism. ${ }^{14}$ Under ER stress, ATF6 translocates to the Golgi apparatus where it is processed to release an active transcription factor contained on its cytosolic domain that upregulates UPR target genes related to stress mitigation.

ER stress-mediated apoptosis. Under acute or prolonged ER stress, the UPR activates a complex cell death program mediated by several components. ${ }^{15}$ This regulation is achieved by the transcriptional and posttranslational modulation of several components of the BCL-2 family that engage the core mitochondrial apoptosis pathway ${ }^{15}$ (Figure 2). Under chronic ER stress, ATF4 contributes to apoptosis by upregulating the transcription factor $\mathrm{C} / \mathrm{EBP}$ homologous protein (CHOP, also known as GADD153), ${ }^{16,17}$ and by enhancing oxidative stress and protein synthesis. ${ }^{18-20}$

Under sustained ER stress, IRE1a is turned off in certain cellular systems, ${ }^{21,22}$ which may attenuate the prosurvival effects of XBP1 expression and upregulate the death receptor DR5, engaging caspase-8 and BID-dependent cell death. ${ }^{23}$ Additionally, the activation of BID by caspase- 2 has also been proposed to contribute to ER stress-mediated cell death through the direct control of miRNAs by IRE1a's RIDD activity $^{24,25}$ (Figure 2), although in some cellular systems caspase-2 was dispensable for ER stress-mediated apoptosis. $^{26}$ IRE1a may also elicit apoptosis through the activation of JNK. ${ }^{27,28} \mathrm{JNK}$ may have an indirect effect on the mitochondria by fine tuning the affinity of $\mathrm{BCL}-2$ to $\mathrm{BH}$-only proteins or by activating proteins like BIM. ${ }^{29,30}$

$\mathrm{BH} 3-$ only proteins are essential to induce ER stressmediated cell death. In fact, triple-deficient cells for the $\mathrm{BH}$ only proteins BIM, PUMA and BID are highly resistant to ER stress, ${ }^{31}$ similar to BAX and BAK double-deficient cells ${ }^{32,33}$ and animals, ${ }^{34}$ indicating a key role of the core proapoptotic program in the induction of apoptosis by ER-related injuries. Several $\mathrm{BH} 3-$ only proteins are induced under acute ER stress including the BH3-only proteins PUMA, NOXA, BAD and BIM. ${ }^{8}$ PUMA and NOXA are transcriptionally upregulated by p53 under ER stress, ${ }^{35}$ whereas BIM can be regulated by phosphorylation or transcriptionally mediated by the UPR transcription factor $\mathrm{CHOP}^{30}$ in addition to be modulated by miRNAs in an ATF4-dependent manner. ${ }^{36}$ Overall, the exact impact of specific BH3-only proteins to apoptosis under ER stress appears to be cell-type and stimuli-dependent.

BOK is a poorly studied BCL-2 family member with extensive amino-acid sequence similarity to BAX and BAK, but with a restrictive expression pattern. ${ }^{37-40}$ Deletion of BOK had no effects on mouse development, and cells derived from these animals did not exhibit any defect in cell death induction, suggesting BOK is dispensable for apoptosis. ${ }^{41-43}$ Nevertheless, recent studies have found that BOK localizes mainly to the ER membrane, where it contributes to apoptosis in response to ER stress. ${ }^{40,44}$ Moreover, recent work has indicated that BOK is constitutively active and directly triggers MOMP-independently of BAX and BAK. ${ }^{45,46}$ Under normal conditions, BOK is continually degraded by the proteasome through the ER-associated degradation (ERAD) pathway. Interestingly, if ERAD and the UPR are altered, BOK is stabilized, translocating to the mitochondria to induce MOMP. ${ }^{45}$ Thus, BOK may function as a direct apoptotic switch in conditions of chronic ER stress.

Taken together, these studies suggests that under irreversible ER stress, UPR signals engage a cluster of BH3-only 


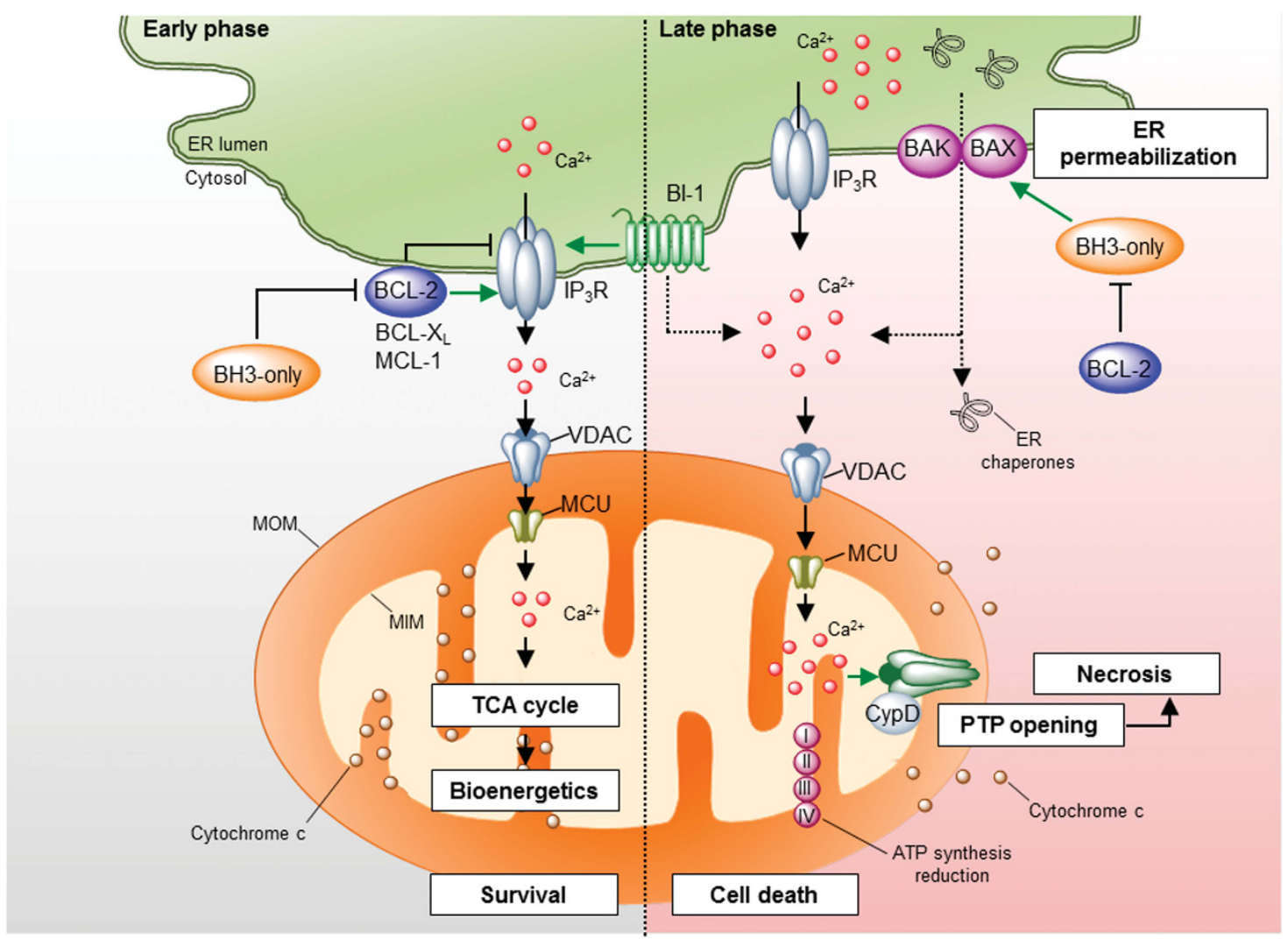

Figure 3 Regulation of ER calcium homeostasis by the BCL-2 family. Different pro- and anti-apoptotic proteins of the BCL-2 family localize to the ER membrane where they regulate $E R$ calcium homeostasis mainly through the modulation of the $\mathrm{IP}_{3} \mathrm{Rs}$. Left panel: under physiological conditions, anti-apoptotic proteins of the $\mathrm{BCL}-2$ family interact with the $\mathrm{IP}_{3} \mathrm{R}$ decreasing its calcium leak activity or promoting the release of oscillatory calcium bursts. This calcium signaling is transduced to the mitochondrial matrix through the VDAC and MCU1 channels at the mitochondria outer and inner membranes, respectively, where it promotes the activity of several metabolic enzymes, increasing ATP production and mitochondrial bioenergetics. The regulation of the $\mathrm{IP}_{3} \mathrm{R}$ by BCL-2 proteins may be antagonized by BH3-only proteins and BAX. BI-1, a protein of the TMBIM family, also interacts with $I P_{3} R$, diminishing ER-to-mitochondria calcium transfer. Right panel: under some apoptotic conditions, $I P_{3} R$ s are activated, leading to sustained calcium release from the ER. Massive calcium uptake by the mitochondria leads to the opening of the mPTP, resulting in mitochondrial swelling, MOMP and decrease in ATP production. This leads to necrotic cell death. Additionally, the ER membrane becomes permeabilized, leading to the release of calcium- and ER-resident proteins. This process is regulated by the proteins of the BCL-2 family. IP $\mathrm{R}$, inositol 1,4,5-trisphosphate receptor; $\mathrm{MCU}$, mitochondrial calcium uniporter; VDAC, voltage-dependent anion channel

proteins, serving as a molecular cross talk between the ER and mitochondria to trigger cell destruction (Figure 2). Overall, the activation of apoptosis by ER stress is complex and does not depend on a unique mechanism (reviewed in Tabas and Ron $\left.{ }^{11}\right)$. A combination of different signaling pathways integrates information at the ER membrane about intensity and duration of the stress toward the activation of BAX, BAK and BOK (Figure 2) (see next sections).

\section{The BCL-2 family and the regulation of ER calcium homeostasis}

The regulation of calcium release from the ER is a relevant modulatory step in determining cell fate in response to a myriad of physiologic and cytotoxic stimuli. Calcium is released from the ER primarily through ER membraneassociated inositol 1,4,5-trisphosphate $\left(\mathrm{IP}_{3}\right)$-gated channels, also called $I_{3}$ receptors $\left(I_{3} R s\right)$. Interestingly, $I_{3} R s$ are distributed in specialized ER subdomains - denominated mitochondria ER-associated membranes (MAMs) - localized in close proximity to the mitochondria. ${ }^{47}$ MAMs facilitate fast and localized calcium transfer, establishing an inter-organelle coupling with important implications for cytosolic calcium buffering, mitochondria metabolism and cell death. ${ }^{47,48}$

The cellular outcome of a rise in cytosolic calcium concentration and its subsequent uptake by the mitochondria depends on the intensity, duration and pattern of the calcium signal itself, and the presence or absence of relevant regulatory proteins. For example, high-frequency cytosolic calcium oscillations or bursts are efficiently transmitted to the mitochondria, resulting in the activation of several calciumdependent mitochondrial enzymes, the F-ATP synthase itself and metabolite carriers, leading to increased mitochondrial respiration and ATP production. ${ }^{48,49}$ On the other hand, sustained calcium release from the ER may overload the mitochondrial matrix triggering a BAX- and BAK-independent mechanism of mitochondrial permeabilization and cytochrome $c$ release known as the mitochondria permeability transition pore (mPTP). ${ }^{50-52}$ The MPTP is associated with the expansion of the mitochondrial matrix, triggering sufficient swelling to rupture the inner and outer mitochondrial membranes, causing the release of apoptotic mediators, including cytochrome $c$, the dissipation of the mitochondrial membrane potential $\left(\Delta \psi_{\mathrm{m}}\right)$ and a sudden decrease of ATP levels. ${ }^{53,54}$ 
The opening of the MPTP is associated with a generalized mitochondrial metabolic dysfunction and necrotic cell death. ${ }^{50}$ Although the molecular identity of the MPTP remains controversial, ${ }^{50}$ different components of the pathway have been proposed, where we highlight Cyclophilin D (CypD) as a major regulator ${ }^{53-56}$ (Figure 3 ). Of note, evidence supporting the existence of a putative BAX/BAK- and CypD-independent pore for cytochrome $c$ release and apoptosis has been provided under conditions of ER stress or calcium unbalance. $^{57,58}$ In this section, we overview a set of reports defining the contribution of the BCL-2 family to the control of ER calcium homeostasis and its impact in mitochondrial biology.

The vast majority of the studies support a role of the BCL-2 family in the control of steady-state ER calcium content and stimulated calcium release. ${ }^{49,59,60}$ In general terms, proapoptotic BCL-2 members promote sustained calcium release engaging the release of cytochrome $c$, while anti-apoptotic BCL-2 proteins exhibit a dual function; inhibiting proapoptotic calcium release and promoting prosurvival oscillatory calcium signaling (reviewed in Rong and Distelhorst ${ }^{49}$ ). Accumulating evidence indicates that the molecular mechanism underlying the control of ER calcium homeostasis by BCL-2 proteins is mediated in part by the $\mathrm{IP}_{3} \mathrm{Rs}$ where two major mechanisms are proposed (Figure 3, left panel). First, BCL-2 interacts with the central modulatory and coupling domain of the $\mathrm{IP}_{3} R$ through the $\mathrm{BH} 4$ domain. ${ }^{59,61,62}$ The functional consequence of this interaction is the inhibition of $\mathrm{IP}_{3}$-mediated calcium release and $I P_{3} R$-induced apoptosis. ${ }^{61,62}$ Second, BCL-2, $\mathrm{BCL}-\mathrm{X}_{\mathrm{L}}$ and $\mathrm{MCL}-1$ directly interact with the C-terminal domain of all three $\mathrm{IP}_{3} \mathrm{R}$ isoforms. ${ }^{63-66}$ In contrast to $\mathrm{BCL}-2-$ mediated inhibition of $I P_{3} R$, these interactions sensitize $I P_{3} R$ s to low levels of $\mathrm{IP}_{3}$, inducing a high-frequency oscillatory calcium release pattern, which is correlated with increased mitochondrial bioenergetics and resistance to cell death. ${ }^{63-65}$ BCL-2 may also modulate the activity of ryanodine receptors. ${ }^{67}$

A fraction of the cellular pool of BAX and BAK resides in the ER membrane. ${ }^{68-70}$ BAX or BAK overexpression causes the
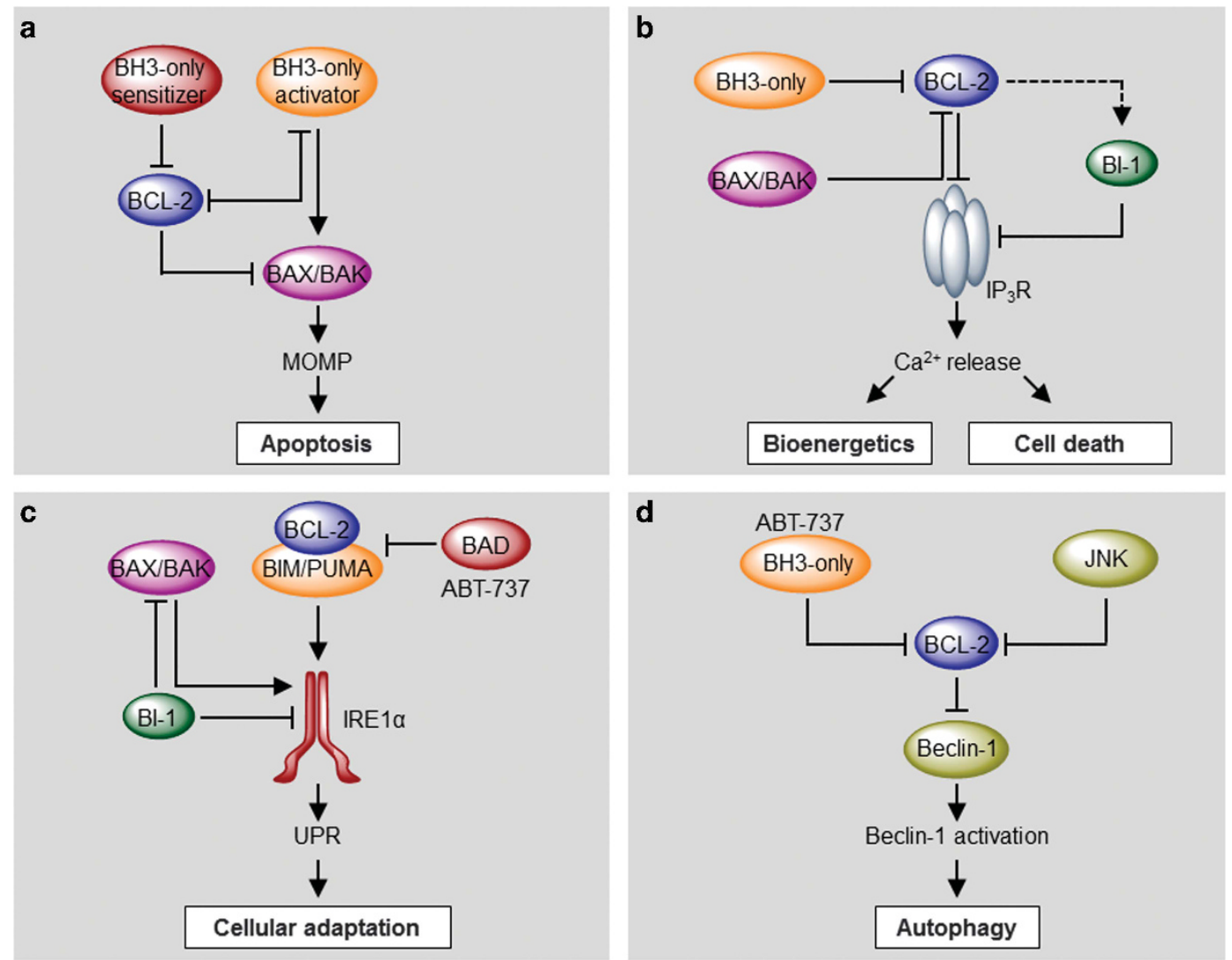

Figure 4 Molecular hierarchical regulation of apoptosis, calcium, the UPR and autophagy by the BCL-2 family of proteins. Different pro- and anti-apoptotic members of the BCL-2 family regulate apoptosis, ER calcium homeostasis, the UPR and autophagy by a complex network of protein-protein interactions with different functional hierarchical organizations. (a) In a combined model of apoptosis regulation by the BCL-2 family, BH3-only activators may directly engage BAX or BAK, causing their homo-oligomerization and MOMP. Anti-apoptotic proteins of the BCL-2 family bind to and sequester activator BH3-only proteins, inhibiting cell death. This inhibitory function may be reversed by sensitizer BH3-only proteins. (b) At the ER membrane, anti-apoptotic BCL-2 interacts with $\mathrm{IP}_{3} \mathrm{R}$ inhibiting its calcium leak channel activity, leading to low transient calcium release and improved mitochondrial bioenergetics. This inhibition may be antagonized by BAX, BAK and proapoptotic BH3-only proteins, increasing ER-to-mitochondrial calcium transfer and triggering mPTP-driven necrosis/apoptosis. Additionally, BI-1 also interacts with and blocks $\mathrm{IP}_{3} \mathrm{R}$, probably downstream of $\mathrm{BCL}-2$ proteins. (c) $\mathrm{BAX}, \mathrm{BAK}, \mathrm{BCL}-2$ and $\mathrm{BH} 3-\mathrm{only}$ proteins BIM and PUMA activate IRE1 $\alpha$ signaling upon ER stress. Interestingly, this function depends on the formation of a protein complex between BIM/PUMA and BCL-2, and can be inhibited by BAD or the BH3 mimetics ABT-737. BI-1 inhibits IRE $1 \alpha$ and BAX/BAK. (d) Anti-apoptotic proteins of the BCL-2 family inhibit autophagy through the interaction with Beclin-1. BH3-only proteins or ABT-737 may displace this inhibitory interaction, releasing Beclin-1 and inducing autophagy. Interestingly, the IRE1 $\alpha / J N K$ pathway may also induce autophagy through the phosphorylation and inhibition of BCL-2 
rapid depletion of ER calcium stores, resulting in increased mitochondrial calcium uptake and cytochrome $c$ release, probably triggering the mPTP. ${ }^{68-70}$ Indeed, restoring the ER calcium content deficit in BAX/BAK double knockout cells by overexpressing the SERCA pump reestablished cell death by $\mathrm{mPTP}$-inducing stimuli, but not by $\mathrm{BH} 3$-only proteins, dissecting the contribution of BCL-2 proteins to MPTP and MOMP. ${ }^{52}$ The exact mechanism by which BAX and BAK induce apoptosis from the ER is not well understood. One hypothesis suggests that BAX and BAK activation at the ER membrane results in increased ER-to-mitochondria calcium transfer, leading to the opening of mPTP and necrotic cell death. ${ }^{52}$ As an alternative, an increase in cytosolic calcium can also lead to Calcineurin activation in the cytosol, indirectly engaging MOMP through the activation of the BH3-only protein BAD. ${ }^{71}$ In addition, the activation of ER stress signals from the ER on a BAX- and BAK-dependent manner may also contribute to apoptosis (see next sections). Several BH3-only proteins also localize to the ER where they modulate ER calcium homeostasis including BIK and PUMA ${ }^{35,72-74}$ Moreover, the physical association of $B C L-X_{L}$ with the $I_{3} R$ can be displaced by $\mathrm{BAX}$ or $\mathrm{BH} 3-$ only proteins, illustrating a model where several proteins of the BCL-2 family converge at the ER membrane to regulate $I P_{3} R$ dynamics, fine tuning mitochondrial function and the susceptibility of cells to undergo apoptosis. Overall, many other studies have linked the activity of $\mathrm{BH} 3-$ only proteins to $\mathrm{ER}$ calcium regulation through the formation of distinct protein complexes with BCL-2 family members at the ER membrane, with a similar biochemical profile to the mitochondrial pool (Figures 3 and $4 b$ ).

\section{Regulation of ER permeability by BAX and BAK}

Early reports indicated that different BCL-2 family members have channel properties with structural similarity to poreforming bacterial toxins. ${ }^{75}$ Indeed, the pore activity of BAX is essential to trigger apoptosis and cytochrome $c$ release, as demonstrated in vitro and in mouse models using small molecule inhibitors that selectively block the channel pore. ${ }^{76}$ Electrophysiological studies have determined that BAX lacks specific conductivity for bivalent cations. ${ }^{77}$ Nevertheless, BAX and BAK form higher-order structures that are permeable to large proteins and dextrans (up to $2 \mathrm{MDa}){ }^{78-80}$ Indeed, using nanoscale super-resolution microscopy, two recent studies have shown BAX forms ring- and arc-like aggregates in the MOM after apoptosis induction, consistent with the presence of an oligomeric proteinaceous pore. ${ }^{81,82}$ These ring-like structures have a diameter ranging from 50 to $700 \mathrm{~nm}$, theoretically allowing the release of large proteins and dextrans, as previously discussed. ${ }^{81,82}$

A few studies suggest that BAX and BAK may also activate and assemble into higher-order oligomers at the ER membrane in response to stress. ${ }^{70,83,84}$ Furthermore, enforced expression of $\mathrm{BH}$-only proteins at the ER membrane causes BAX oligomerization at the ER membrane, a phenomenon inhibited by $B C L-2^{73,84}$ (Figure 3 ). The ER membrane itself may become permeabilized under ER stress conditions, a phenomena regulated by the BCL- 2 family. ${ }^{83}$ ER luminal chaperones including Grp78/BiP, Grp94, calreticulin and PDI are released into the cytosol in a BAX- and BAK-dependent manner. This process is initiated by upstream BH3-only proteins and antagonized by $\mathrm{BCL}-\mathrm{X}_{\mathrm{L}}$ and $\mathrm{BCL}-2 .{ }^{83,85}$ Although the role of the released protein in apoptosis is not clear, another report suggested that the translocation of certain disulfide isomerases (i.e., PDI) to the ER-mitochondrial contact sites contribute to cell death in models of neurodegeneration. ${ }^{86}$ Thus, the biochemical interactions regulating this putative $E R$ permeabilization resemble the hierarchical control of MOMP. Interestingly, it was recently found that the UPR sensor IRE1a plays a critical role in the regulation of ER membrane permeabilization under ER stress, a phenomenon mediated by the $\mathrm{BH} 3-$ only protein $\mathrm{BNip} 3 .^{85}$

Although the significance of ER permeabilization to cell death needs to be further determined, we speculate that this process may (i) induce a massive release of ER calcium engaging mPTP or calcium-dependent cytosolic enzymes (e.g., Calcineurin), (ii) deplete the ER of essential folding components, exacerbating ER stress and affecting protein trafficking and (iii) enhance ROS production through altered ER redox and mitochondrial bioenergetics.

\section{Additional players in ER-to-mitochondria cross talk: BAX inhibitor 1 and the TMBIM family}

In addition to the BCL-2 family, several other proteins are involved in the regulation of ER calcium dynamics and apoptosis at the ER membrane. The transmembrane BAX inhibitor motif containing (TMBIM) family is composed of at least six highly conserved members that play a critical role in apoptosis and calcium regulation in response to several cell death stimuli. ${ }^{87}$ The TMBIM family of proteins is highly conserved throughout evolution, with homologs in species where no BCL-2 members have been described, including bacteria, yeast and plants. ${ }^{87,88}$ TMBIM family members are characterized by the presence of up to seven transmembrane domains and the UPF0005 motif of unknown function, and includes the following members: centrifugal force and shear stress (RECS1/TMBIM1), lifeguard (LFG/TMBIM2), glutamate receptor ionotropic NMDA-associated protein 1 (GRINA/ TMBIM3), Golgi anti-apoptotic protein (GAAP/TMBIM4), growth hormone inducible transmembrane protein (GHITM/ TMBIM5) and BAX inhibitor 1 (BI-1/TMBIM6). ${ }^{87}$ All TMBIM family members are implicated in apoptosis inhibition by different mechanisms. ${ }^{87}$ The crystal structure of the Bacillus subtilis TMBIM homolog BsYetJ was solved, revealing a seven transmembrane $\mathrm{pH}$-sensitive calcium channel. ${ }^{89}$ Cation conductivity has been demonstrated for the human homologs $\mathrm{Bl}-1$ and GAAP, proposing a general mechanism for the entire TMBIM family in the regulation of cell death. ${ }^{90}$

$\mathrm{BI}-1$ is the founder member of the family, first identified in yeast screenings for inhibitors of cell death triggered by BAX overexpression. $^{91}$ We reported a functional relationship between components of the TMBIM family, observing that $\mathrm{BI}-1$ and GRINA control cell death under ER stress conditions, having synergistic and complementary activities in the regulation of apoptosis. $^{92,93} \mathrm{BI}-1$ and GRINA physically interact, and are embedded within the ER membrane where they specifically inhibit cell death triggered by ER stress, possibly through the modulation of ER calcium dynamics by interactions with the $\mathrm{IP}_{3} \mathrm{Rs} .^{92-95} \mathrm{BI}-1$ may also modulate 
apoptosis in part through the induction of mPTP. ${ }^{96}$ Thus, members of the TMBIM family regulate cell death indirectly, possibly through the modulation of calcium signaling across different intracellular membranes. It remains to be determined if TMBIM family members antagonize BH3-only proteins or alter the activity of multidomain BCL-2 family members.

What is the relationship between the TMBIM and the BCL-2 protein family? $\mathrm{BI}-1$ is required for the regulation of $\mathrm{ER}$ calcium content downstream of the BCL-2 family. ${ }^{95} \mathrm{BI}-1$ and GRINA physically interact with $B C L-2$ and $B C L-X_{L},{ }^{21,92,93}$ and the $\mathrm{BH} 4$ motifs of these proteins enhance $\mathrm{Bl}-1$ oligomerization and calcium efflux. ${ }^{97}$ Since $\mathrm{BI}-1$ has recently been identified as a $\mathrm{pH}$-sensitive calcium leak channel, an interesting hypothesis is that BCL-2 family members regulate TMBIM channel gating properties by direct interactions, in a manner analogous to their regulation of $\mathrm{IP}_{3} \mathrm{Rs} .{ }^{89}$ Further studies are needed to fully elucidate the role of BCL-2-related proteins in the regulation of calcium dynamics and its possible connection with the TMBIM family of proteins.

\section{Stress signal integration at the ER membrane by the BCL-2 family}

In the last decade, the ER membrane has emerged as a hub where different stress signals are integrated to determine cell fate decisions. ${ }^{5,98}$ Accumulating evidence suggest a new concept where members of the BCL-2 families operate as stress signal integration platforms through physical interactions that control the activity of key core components of distinct stress pathways (Figure 4). At the molecular level, a remarkable triade is emerging where the apoptosis, UPR and autophagy machineries converge into interrelated protein complexes at the ER membrane through interactions with BCL-2 family members, affecting global proteostasis in addition to mitochondrial bioenergetics. In this section we summarize a few examples depicting the cross talk between key apoptosis regulatory proteins and central stress pathways to modulate adaptation processes or cell demise

Fine tuning the UPR by the BCL-2 family. Accumulating studies indicate that a variety of apoptosis-related proteins physically interact with the ER stress sensor IRE1a, regulating the threshold to engage UPR responses. ${ }^{12}$ IRE $1 a$ is proposed to operate as a scaffold, where many regulators assemble to modulate ER stress signaling and the cross talk with diverse stress pathways through a platform referred to as the UPRosome. ${ }^{99}$ We initially reported that BAX and BAK instigate UPR responses (i.e., JNK and XBP1). ${ }^{34}$ In certain experimental systems, BH3-only proteins such as BIM and PUMA can enhance IRE1a activation through a physical interaction. ${ }^{100}$ Unexpectedly, the expression of BCL-2 was required for this positive regulation, whereas $B A D$ or the $B H 3$ mimetic ABT-737 antagonized this pathway, ${ }^{100}$ suggesting that the basal antagonized complex operates to control the UPR (Figure 4c). Alternatively, BCL-2 may modulate global ER stress signaling through unknown mechanisms. ${ }^{101} \mathrm{BI}-1$ has a relevant activity in attenuating IRE1a signaling under prolonged ER stress also involving the formation of a protein complex that competes for BAX.21,102,103 Many other apoptosis-related proteins also associate with $\operatorname{IRE} 1 a,{ }^{12,99}$ supporting the concept that apoptosis-related proteins have an alternative role at the ER, modulating the threshold to induce or attenuate ER stress (Figure 4c).

Regulation of macroautophagy by the BCL-2 family. The BCL-2 family also has relevant activities at the ER to control the levels of autophagy, an adaptive response that has a prosurvival function under nutrient starvation but also ER stress. ${ }^{104}$ However, overactivation of autophagy may be detrimental. ${ }^{105}$ There is a coordinated regulatory cross talk between the UPR (early stages) and the induction of autophagy. Autophagy is regulated at the ER membrane through the sequestration and consequent inhibition of Beclin-1 - one of the key players in autophagy induction by anti-apoptotic members of the BCL-2 family. ${ }^{106-109}$ Beclin1 carries a $\mathrm{BH} 3$-like motif and interacts with the groove of $B C L-2, B C L-X_{L}$ and $M C L-1$ in an analogous manner as BH3only proteins ${ }^{107-109}$ (Figure 4d). However, Beclin-1 does not have a proapoptotic activity. ${ }^{110}$ In addition, the interaction between Beclin-1 and BCL-2 can be modulated by BH3-only proteins and $\mathrm{BH} 3$ mimetics like ABT-737. ${ }^{108,109}$ Upon aminoacid starvation or ER stress, BCL-2 becomes phosphorylated within its $\mathrm{N}$-terminal unstructured loop, disrupting its interaction with Beclin-1 and resulting in autophagy induction. ${ }^{111,112}$ $\mathrm{BH} 3-$ only proteins also enhance autophagy by disrupting the Beclin-1/BCL-2 interaction. ${ }^{107,111-113}$ Although several laboratories have provided evidence supporting the connection between Beclin-1 and BCL-2 family members, recent studies have challenged this model, proposing an alternative mechanism whereby prosurvival BCL-2 proteins inhibit autophagy only indirectly, through their interaction with and sequestration of proapoptotic BAX and BAK. ${ }^{114,115}$ However, another study indicated that BAX and BAK are dispensable for ABT-737-induced autophagy. ${ }^{116}$ Further studies are necessary to precisely determine the functional interplay between the BCL-2 family and components of the autophagy machinery.

$\mathrm{Bl}-1$ has a relevant activity in regulating autophagy through its repressor activity on the IRE1a/JNK pathway, affecting the phosphorylation of the BCL-X $/$ Beclin-1 complex at the ER. ${ }^{117}$ Besides, $\mathrm{BI}-1$ may also enhance autophagy under certain conditions through the release of calcium and activation of AMP kinase. ${ }^{118,119}$ Although a similar activity has been reported for the $\mathrm{IP}_{3} \mathrm{Rs},{ }^{120} \mathrm{BCL}-2$ and $\mathrm{BCL}-\mathrm{X}_{\mathrm{L}}$ have a clear inhibitory activity on autophagy through Beclin-1, similar to $\mathrm{BI}-1 .{ }^{117}$ Thus, the interplay between members of the BCL-2 and TMBIM families at the ER membrane integrates stress responses through the formation of distinct protein complexes, in addition to modulate ER calcium homeostasis and its metabolic control with the mitochondria.

\section{Concluding remarks}

Here we have overviewed emerging evidence supporting a complex interplay between the BCL-2 family of proteins at the ER with several factors involved in stress signaling and the control of mitochondrial-dependent apoptosis. Dynamic protein complexes are assembled at the ER membrane to fine tune and integrate multiple stress responses that set the global threshold for apoptosis induction. At the center of this 


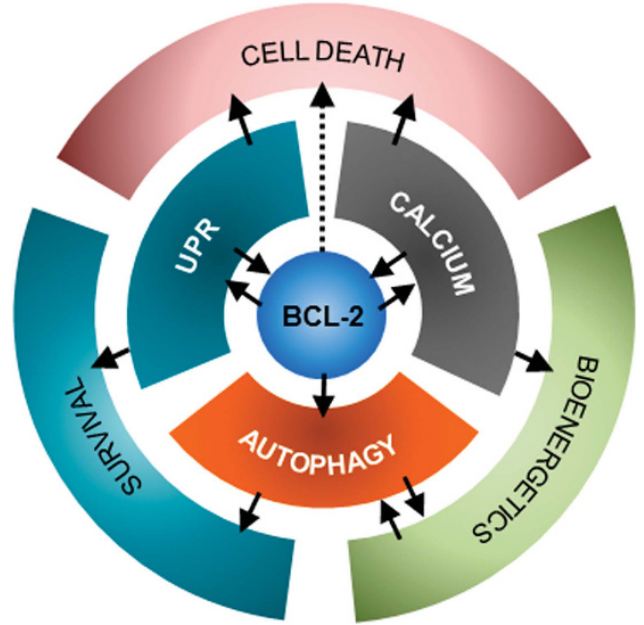

Figure 5 Integrating stress responses at the ER. The ER pool of proteins of the BCL-2 family plays a central role in the regulation of the UPR, calcium homeostasis and autophagy, acting as molecular bridges between these stress pathways. Additionally, the activation of these pathways may lead to different cellular outcomes, such as improved bioenergetics and survival or cell death. Bidirectional regulations and cross talk are indicated with arrows. Thus, the BCL-2 family at the ER plays a pivotal role in cell fate determination upon ER stress

regulation, the BCL-2 and TMBIM families play a key role in the cross talk and integration of multiple signaling pathways that control the maintenance of global proteostasis and mitochondrial bioenergetics. Accordingly, beyond the regulation of MOMP, BCL-2- and TMBIM-related proteins have distinct activities at the ER membrane to control ER calcium dynamics, UPR activation, autophagy levels and ER permeabilization. In general terms, multiple bidirectional regulation points can be identified, reflecting the dynamic nature of interactions that orchestrate global outputs in response to cellular and environmental stress to engage adaptive programs, mitochondrial bioenergetics or cell death (Figure 5).

Given the existence of diverse novel functions of the BCL-2 and TMBIM families in physiological processes beyond apoptosis, it has been suggested that these proteins act as specialized 'stress sentinels', operating as molecular switches to transit between prosurvival responses and the induction of the core apoptosis pathway in response to irreversible stress. ${ }^{8}$ Since several small molecules have been designed to target BCL-2 family members for the treatment of cancer, ${ }^{7}$ it is essential to consider possible side effects of targeting the core apoptosis pathways in other-related processes including ERrelated functions.

\section{Conflict of Interest}

The authors declare no conflict of interest.

Acknowledgements. This work was funded by FONDECYT no. 3150113 (AC), FONDECYT no. 1140549, FONDAP program 15150012, Millennium Institute P09015-F, European Commission R\&D MSCA-RISE \#734749 (CH). We also thank the support from Michael J Fox Foundation for Parkinson's Research - Target Validation grant No 9277, FONDEF ID16110223, FONDEF D11E1007, US Office of Naval Research-Global (ONR-G) N62909-16-1-2003, U.S. Air Force Office of Scientific Research FA9550-16-1-0384, ALSRP Therapeutic Idea Award AL150111, Muscular
Dystrophy Association 382453 and CONICYT-Brazil 441921/2016-7 (CH). PP is a postgraduate fellow supported by a CONICYT fellowship.

1. Youle RJ, Strasser A. The BCL-2 protein family: opposing activities that mediate cell death Nat Rev Mol Cell Biol 2008; 9: 47-59.

2. Tait SW, Green DR. Mitochondria and cell death: outer membrane permeabilization and beyond. Nat Rev Mol Cell Biol 2010; 11: 621-632.

3. Kerr JF, Wyllie AH, Currie AR. Apoptosis: a basic biological phenomenon with wide-ranging implications in tissue kinetics. Br J Cancer 1972; 26: 239-257.

4. Taylor RC, Cullen SP, Martin SJ. Apoptosis: controlled demolition at the cellular level. Nat Rev Mol Cell Biol 2008; 9: 231-241.

5. Galluzzi L, Bravo-San Pedro JM, Kroemer G. Organelle-specific initiation of cell death. Nat Cell Biol 2014; 16: 728-736.

6. Volkmann N, Marassi FM, Newmeyer DD, Hanein D. The rheostat in the membrane: BCL-2 family proteins and apoptosis. Cell Death Differ 2014; 21: 206-215.

7. Czabotar PE, Lessene G, Strasser A, Adams JM. Control of apoptosis by the BCL-2 protein family: implications for physiology and therapy. Nat Rev Mol Cell Biol 2014; 15: 49-63.

8. Hetz $C$, Glimcher $L$. The daily job of night killers: alternative roles of the $B C L-2$ family in organelle physiology. Trends Cell Biol 2008; 18: 38-44.

9. Walter $P$, Ron D. The unfolded protein response: from stress pathway to homeostatic regulation. Science 2011; 334: 1081-1086

10. Wang M, Kaufman RJ. Protein misfolding in the endoplasmic reticulum as a conduit to human disease. Nature 2016; 529: 326-335.

11. Tabas I, Ron D. Integrating the mechanisms of apoptosis induced by endoplasmic reticulum stress. Nat Cell Biol 2011; 13: 184-190.

12. Hetz $\mathrm{C}$. Chevet $\mathrm{E}$, Oakes SA. Proteostasis control by the unfolded protein response. Nat Cell Biol 2015; 17: 829-838.

13. Maurel M. Chevet E, Tavernier J, Gerlo S. Getting RIDD of RNA: IRE1 in cell fate regulation. Trends Biochem Sci 2014; 39: 245-254.

14. Harding HP, Novoa I, Zhang Y, Zeng H, Wek R, Schapira M et al. Regulated translation initiation controls stress-induced gene expression in mammalian cells. Mol Cell 2000; 6 : 1099-1108.

15. Urra H, Dufey E, Lisbona F, Rojas-Rivera D, Hetz C. When ER stress reaches a dead end. Biochim Biophys Acta 2013; 1833: 3507-3517.

16. Zinszner H, Kuroda M, Wang X, Batchvarova N, Lightfoot RT, Remotti $\mathrm{H}$ et al. CHOP is implicated in programmed cell death in response to impaired function of the endoplasmic reticulum. Genes Dev 1998; 12: 982-995.

17. Matsumoto M, Minami M, Takeda K, Sakao Y, Akira S. Ectopic expression of $\mathrm{CHOP}$ (GADD153) induces apoptosis in M1 myeloblastic leukemia cells. FEBS Lett 1996; 395 143-147.

18. Harding HP, Zhang Y, Zeng H, Novoa I, Lu PD, Calfon M et al. An integrated stress response regulates amino acid metabolism and resistance to oxidative stress. $\mathrm{Mol} \mathrm{Cell}$ 2003; 11: 619-633.

19. Marciniak SJ, Yun CY, Oyadomari S, Novoa I, Zhang Y, Jungreis R et al. CHOP induces death by promoting protein synthesis and oxidation in the stressed endoplasmic reticulum. Genes Dev 2004; 18: 3066-3077.

20. Han J, Back SH, Hur J, Lin YH, Gildersleeve R, Shan J et al. ER-stress-induced transcriptional regulation increases protein synthesis leading to cell death. Nat Cell Biol 2013; 15: 481-490.

21. Lisbona F, Rojas-Rivera D, Thielen $P$, Zamorano S, Todd D, Martinon F et al. BAX inhibitor1 is a negative regulator of the ER stress sensor IRE1alpha. Mol Cell 2009; 33: 679-691.

22. Lin JH, Li H, Yasumura D, Cohen HR, Zhang C, Panning B et al. IRE1 signaling affects cell fate during the unfolded protein response. Science 2007; 318: 944-949.

23. Lu M, Lawrence DA, Marsters S, Acosta-Alvear D, Kimmig P, Mendez AS et al. Opposing unfolded-protein-response signals converge on death receptor 5 to control apoptosis. Science 2014; 345: 98-101.

24. Upton JP, Austgen K, Nishino M, Coakley KM, Hagen A, Han D et al. Caspase-2 cleavage of BID is a critical apoptotic signal downstream of endoplasmic reticulum stress. Mol Cell Biol 2008; 28: 3943-3951.

25. Upton JP, Wang L, Han D, Wang ES, Huskey NE, Lim L et al. IRE1alpha cleaves select microRNAs during ER stress to derepress translation of proapoptotic Caspase-2. Science 2012; 338: 818-822.

26. Sandow JJ, Dorstyn L, O'Reilly LA, Tailler M, Kumar S, Strasser A et al. ER stress does not cause upregulation and activation of caspase-2 to initiate apoptosis. Cell Death Differ 2014; 21: $475-480$.

27. Hu P, Han Z, Couvillon AD, Kaufman RJ, Exton JH. Autocrine tumor necrosis factor alpha links endoplasmic reticulum stress to the membrane death receptor pathway through IRE1alpha-mediated NF-kappaB activation and down-regulation of TRAF2 expression. Mol Cell Biol 2006; 26: 3071-3084.

28. Nishitoh H, Matsuzawa A, Tobiume K, Saegusa K, Takeda K, Inoue K et al. ASK1 is essential for endoplasmic reticulum stress-induced neuronal cell death triggered by expanded polyglutamine repeats. Genes Dev 2002; 16: 1345-1355

29. Bassik MC, Scorrano L, Oakes SA, Pozzan T, Korsmeyer SJ. Phosphorylation of BCL-2 regulates ER Ca2+ homeostasis and apoptosis. EMBO J 2004; 23: 1207-1216.

30. Puthalakath H, O'Reilly LA, Gunn P, Lee L, Kelly PN, Huntington ND et al. ER stress triggers apoptosis by activating BH3-only protein Bim. Cell 2007; 129: 1337-1349. 
31. Ren D, Tu HC, Kim H, Wang GX, Bean GR, Takeuchi $O$ et al. BID, BIM, and PUMA are essential for activation of the BAX-and BAK-dependent cell death program. Science 2010; 330: $1390-1393$.

32. Wei MC, Zong WX, Cheng EH, Lindsten T, Panoutsakopoulou V, Ross AJ et al. Proapoptotic BAX and BAK: a requisite gateway to mitochondrial dysfunction and death. Science 2001; 292: 727-730.

33. Lindsten T, Ross AJ, King A, Zong WX, Rathmell JC, Shiels HA et al. The combined functions of proapoptotic Bcl-2 family members bak and bax are essential for normal development of multiple tissues. Mol Cell 2000; 6: 1389-1399.

34. Hetz C, Bernasconi P, Fisher J, Lee AH, Bassik MC, Antonsson B et al. Proapoptotic BAX and BAK modulate the unfolded protein response by a direct interaction with IRE1alpha. Science 2006; 312: 572-576.

35. Li J, Lee B, Lee AS. Endoplasmic reticulum stress-induced apoptosis: multiple pathways and activation of p53-up-regulated modulator of apoptosis (PUMA) and NOXA by p53. $J$ Biol Chem 2006; 281: 7260-7270.

36. Gupta S, Read DE, Deepti A, Cawley K, Gupta A, Oommen D et al. Perk-dependent repression of miR-106b-25 cluster is required for ER stress-induced apoptosis. Cell Death Dis 2012; 3: e333.

37. Hsu SY, Hsueh AJ. A splicing variant of the Bcl-2 member Bok with a truncated BH3 domain induces apoptosis but does not dimerize with antiapoptotic Bcl-2 proteins in vitro. Biol Chem 1998; 273: 30139-30146.

38. Hsu SY, Kaipia A, McGee E, Lomeli M, Hsueh AJ. Bok is a pro-apoptotic Bcl-2 protein with restricted expression in reproductive tissues and heterodimerizes with selective antiapoptotic Bcl-2 family members. Proc Natl Acad Sci USA 1997; 94: 12401-12406.

39. Inohara N, Ekhterae D, Garcia I, Carrio R, Merino J, Merry A et al. Mtd, a novel Bcl-2 family member activates apoptosis in the absence of heterodimerization with $\mathrm{Bcl}-2$ and $\mathrm{Bcl}-\mathrm{XL}$. $J$ Biol Chem 1998; 273: 8705-8710.

40. Echeverry N, Bachmann D, Ke F, Strasser A, Simon HU, Kaufmann T. Intracellular localization of the BCL-2 family member BOK and functional implications. Cell Death Differ 2013; 20: 785-799.

41. Ke F, Bouillet P, Kaufmann T, Strasser A, Kerr J, Voss AK. Consequences of the combined loss of BOK and BAK or BOK and BAX. Cell Death Dis 2013; 4: e650.

42. Ke F, Voss A, Kerr JB, O'Reilly LA, Tai L, Echeverry N et al. BCL-2 family member BOK is widely expressed but its loss has only minimal impact in mice. Cell Death Differ 2012; 19 915-925.

43. Ke F, Grabow S, Kelly GL, Lin A, O'Reilly LA, Strasser A. Impact of the combined loss of $B O K, B A X$ and BAK on the hematopoietic system is slightly more severe than compound loss of BAX and BAK. Cell Death Dis 2015; 6: e1938.

44. Carpio MA, Michaud M, Zhou W, Fisher JK, Walensky LD, Katz SG. BCL-2 family member BOK promotes apoptosis in response to endoplasmic reticulum stress. Proc Natl Acad Sci USA 2015; 112: 7201-7206.

45. Llambi F, Wang YM, Victor B, Yang M, Schneider DM, Gingras S et al. BOK is a noncanonical BCL-2 family effector of apoptosis regulated by ER-associated degradation. Cell 2016; 165: 421-433

46. Einsele-Scholz S, Malmsheimer S, Bertram K, Stehle D, Johanning J, Manz M et al. Bok is a genuine multi-BH-domain protein that triggers apoptosis in the absence of Bax and Bak. $J$ Cell Sci 2016; 129: 2213-2223.

47. Phillips MJ, Voeltz GK. Structure and function of ER membrane contact sites with other organelles. Nat Rev Mol Cell Biol 2016; 17: 69-82.

48. Rizzuto R, De Stefani D, Raffaello A, Mammucari C. Mitochondria as sensors and regulators of calcium signalling. Nat Rev Mol Cell Biol 2012; 13: 566-578.

49. Rong $Y$, Distelhorst $\mathrm{CW}$. Bcl-2 protein family members: versatile regulators of calcium signaling in cell survival and apoptosis. Annu Rev Physiol 2008; 70: 73-91.

50. Bernardi P, Rasola A, Forte M, Lippe G. The mitochondrial permeability transition pore: channel formation by F-ATP synthase, integration in signal transduction, and role in pathophysiology. Physiol Rev 2015; 95: 1111-1155

51. Deniaud A. Sharaf el dein O, Maillier E, Poncet D, Kroemer G, Lemaire C et al. Endoplasmic reticulum stress induces calcium-dependent permeability transition, mitochondrial outer membrane permeabilization and apoptosis. Oncogene 2008; 27: 285-299.

52. Scorrano L, Oakes SA, Opferman JT, Cheng EH, Sorcinelli MD, Pozzan T et al. BAX and BAK regulation of endoplasmic reticulum Ca2t: a control point for apoptosis. Science 2003 300: 135-139.

53. Nakagawa T, Shimizu S, Watanabe T, Yamaguchi O, Otsu K, Yamagata H et al. Cyclophilin D-dependent mitochondrial permeability transition regulates some necrotic but not apoptotic cell death. Nature 2005; 434: 652-658.

54. Baines CP, Kaiser RA, Purcell NH, Blair NS, Osinska H, Hambleton MA et al. Loss of cyclophilin $D$ reveals a critical role for mitochondrial permeability transition in cell death. Nature 2005; 434: 658-662.

55. Basso E, Fante L, Fowlkes J, Petronilli V, Forte MA, Bernardi P. Properties of the permeability transition pore in mitochondria devoid of Cyclophilin D. J Biol Chem 2005; 280 18558-18561.

56. Schinzel AC, Takeuchi O, Huang Z, Fisher JK, Zhou Z, Rubens J et al. Cyclophilin D is a component of mitochondrial permeability transition and mediates neuronal cell death after focal cerebral ischemia. Proc Natl Acad Sci USA 2005; 102: 12005-12010.

57. Zamorano S, Rojas-Rivera D, Lisbona F, Parra V, Court FA, Villegas R et al. A BAX/BAK and cyclophilin D-independent intrinsic apoptosis pathway. PLOS ONE 2012 7: e37782.
58. Mizuta T, Shimizu S, Matsuoka Y, Nakagawa T, Tsujimoto Y. A Bax/Bak-independent mechanism of cytochrome c release. J Biol Chem 2007; 282: 16623-16630.

59. Monaco G, Decrock E, Akl H, Ponsaerts R, Vervliet T, Luyten T et al. Selective regulation of IP3-receptor-mediated $\mathrm{Ca} 2+$ signaling and apoptosis by the $\mathrm{BH} 4$ domain of $\mathrm{Bcl}-2$ versus Bcl-Xl. Cell Death Differ 2012; 19: 295-309.

60. Kiviluoto S, Luyten T, Schneider L, Lisak D, Rojas-Rivera D, Welkenhuyzen K et al. Bax inhibitor-1-mediated Ca2+ leak is decreased by cytosolic acidosis. Cell Calcium 2012; 54 : 186-192x.

61. Rong YP, Aromolaran AS, Bultynck G, Zhong F, Li X, McColl K et al. Targeting Bcl-2-IP3 receptor interaction to reverse Bcl-2's inhibition of apoptotic calcium signals. Mol Cell 2008; 31: 255-265.

62. Rong YP, Bultynck G, Aromolaran AS, Zhong F, Parys JB, De Smedt H et al. The BH4 domain of Bcl-2 inhibits ER calcium release and apoptosis by binding the regulatory and coupling domain of the IP3 receptor. Proc Natl Acad Sci USA 2009; 106: 14397-14402

63. White C, Li C, Yang J, Petrenko NB, Madesh M, Thompson CB et al. The endoplasmic reticulum gateway to apoptosis by $\mathrm{Bcl}-\mathrm{X}(\mathrm{L})$ modulation of the InsP3R. Nat Cell Biol 2005; 7 : $1021-1028$

64. Eckenrode EF, Yang J, Velmurugan GV, Foskett JK, White C. Apoptosis protection by Mcl-1 and $\mathrm{Bcl}-2$ modulation of inositol 1,4,5-trisphosphate receptor-dependent $\mathrm{Ca} 2+$ signaling. J Biol Chem 2010; 285: 13678-13684.

65. Yang J, Vais H, Gu W, Foskett JK. Biphasic regulation of InsP3 receptor gating by dual $\mathrm{Ca} 2+$ release channel $\mathrm{BH} 3$-like domains mediates $\mathrm{Bcl}-\mathrm{XL}$ control of cell viability. Proc Natl Acad Sci USA 2016; 113: E1953-1962.

66. Li C, Wang X, Vais $\mathrm{H}$, Thompson CB, Foskett JK, White C. Apoptosis regulation by Bcl-x(L) modulation of mammalian inositol 1,4,5-trisphosphate receptor channel isoform gating. Proc Natl Acad Sci USA 2007; 104: 12565-12570.

67. Vervliet T, Decrock E, Molgo J, Sorrentino V, Missiaen L, Leybaert L et al. Bcl-2 binds to and inhibits ryanodine receptors. J Cell Sci 2014; 127: 2782-2792.

68. Nutt LK, Chandra J, Pataer A, Fang B, Roth JA, Swisher SG et al. Bax-mediated Ca2+ mobilization promotes cytochrome $\mathrm{c}$ release during apoptosis. J Biol Chem 2002; 277: 20301-20308

69. Nutt LK, Pataer A, Pahler J, Fang B, Roth J, McConkey DJ et al. Bax and Bak promote apoptosis by modulating endoplasmic reticular and mitochondrial Ca2+ stores. J Biol Chem 2002; 277: 9219-9225.

70. Zong WX, Li C, Hatzivassiliou G, Lindsten T, Yu QC, Yuan J et al. Bax and Bak can localize to the endoplasmic reticulum to initiate apoptosis. J Cell Biol 2003; 162: 59-69.

71. Wang HG. Pathan N, Ethell IM, Krajewski S, Yamaguchi Y, Shibasaki F et al. Ca2+-induced apoptosis through calcineurin dephosphorylation of BAD. Science 1999; 284: 339-343.

72. Germain M, Mathai JP, Shore GC, BH-3-only BIK. functions at the endoplasmic reticulum to stimulate cytochrome c release from mitochondria. J Biol Chem 2002; 277: 18053-18060.

73. Mathai JP, Germain M, Shore GC, BH3-only BIK. regulates BAX, BAK-dependent release of $\mathrm{Ca} 2+$ from endoplasmic reticulum stores and mitochondrial apoptosis during stressinduced cell death. J Biol Chem 2005; 280: 23829-23836.

74. Shibue T, Suzuki S, Okamoto H, Yoshida H, Ohba Y, Takaoka A et al. Differential contribution of Puma and Noxa in dual regulation of p53-mediated apoptotic pathways. EMBO J 2006; 25: 4952-4962

75. Schendel SL, Montal M, Reed JC. Bcl-2 family proteins as ion-channels. Cell Death Differ 1998: 5: 372-380.

76. Hetz C, Vitte PA, Bombrun A, Rostovtseva TK, Montessuit S, Hiver A et al. Bax channel inhibitors prevent mitochondrion-mediated apoptosis and protect neurons in a model of global brain ischemia. J Biol Chem 2005; 280: 42960-42970.

77. Schlesinger PH, Gross A, Yin XM, Yamamoto K, Saito M, Waksman G et al. Comparison of the ion channel characteristics of proapoptotic BAX and antiapoptotic BCL-2. Proc Nat Acad Sci USA 1997; 94: 11357-11362.

78. Kuwana T, Mackey MR, Perkins G, Ellisman MH, Latterich M, Schneiter R et al. Bid, Bax, and lipids cooperate to form supramolecular openings in the outer mitochondrial membrane. Cell 2002; 111: 331-342.

79. Munoz-Pinedo C, Guio-Carrion A, Goldstein JC, Fitzgerald P, Newmeyer DD, Green DR. Different mitochondrial intermembrane space proteins are released during apoptosis in a manner that is coordinately initiated but can vary in duration. Proc Natl Acad Sci USA 2006; 103: 11573-11578.

80. Rehm M, Huber HJ, Hellwig CT, Anguissola S, Dussmann H, Prehn JH. Dynamics of outer mitochondrial membrane permeabilization during apoptosis. Cell Death Differ 2009; 16 : 613-623.

81. Grosse L, Wurm CA, Bruser C, Neumann D, Jans DC, Jakobs S. Bax assembles into large ring-like structures remodeling the mitochondrial outer membrane in apoptosis. EMBO J 2016; 35: 402-413.

82. Salvador-Gallego R, Mund M, Cosentino K, Schneider J, Unsay J, Schraermeyer U et al. Bax assembly into rings and arcs in apoptotic mitochondria is linked to membrane pores. EMBO J 2016; 35: 389-401.

83. Wang $\mathrm{X}$, Olberding KE, White C, Li C. Bcl-2 proteins regulate ER membrane permeability to luminal proteins during ER stress-induced apoptosis. Cell Death Differ 2011; 18: 38-47.

84. Klee M, Pallauf K, Alcala S, Fleischer A, Pimentel-Muinos FX. Mitochondrial apoptosis induced by $\mathrm{BH} 3-$ only molecules in the exclusive presence of endoplasmic reticular Bak. EMBO J 2009; 28: 1757-1768. 
85. Kanekura K, Ma X, Murphy JT, Zhu LJ, Diwan A, Urano F. IRE1 prevents endoplasmic reticulum membrane permeabilization and cell death under pathological conditions. Sci Signal 2015; 8: ra62.

86. Hoffstrom BG, Kaplan A, Letso R, Schmid RS, Turmel GJ, Lo DC et al. Inhibitors of protein disulfide isomerase suppress apoptosis induced by misfolded proteins. Nat Chem Biol 2010; 6: 900-906.

87. Rojas-Rivera D, Hetz C. TMBIM protein family: ancestral regulators of cell death. Oncogene 2014; 2014: 6.

88. Hu L, Smith TF, Goldberger G. LFG: a candidate apoptosis regulatory gene family. Apoptosis 2009; 14: 1255-1265.

89. Chang Y, Bruni R, Kloss B, Assur Z, Kloppmann E, Rost B et al. Structural basis for a pHsensitive calcium leak across membranes. Science 2014; 344: 1131-1135.

90. CarraraSaraiva G, Parsons N, Byrne M, Prole B, Taylor DL. CW et al. Golgi anti-apoptotic proteins are highly conserved ion channels that affect apoptosis and cell migration. J Biol Chem 2015; 290: 11785-11801.

91. Xu Q, Reed JC. Bax inhibitor-1, a mammalian apoptosis suppressor identified by functional screening in yeast. Mol Cell 1998; 1: 337-346.

92. Chae HJ, Kim HR, Xu C, Bailly-Maitre B, Krajewska M, Krajewski S et al. BI-1 regulates an apoptosis pathway linked to endoplasmic reticulum stress. Mol Cell 2004; 15: 355-366.

93. Rojas-Rivera D, Armisen R, Colombo A, Martinez G, Eguiguren AL, Diaz A et al. TMBIM3/GRINA is a novel unfolded protein response (UPR) target gene that controls apoptosis through the modulation of ER calcium homeostasis. Cell Death Differ 2012; 19 : 1013-1026.

94. Kim HR, Lee GH, Ha KC, Ahn T, Moon JY, Lee BJ et al. Bax Inhibitor-1 is a pH-dependent regulator of $\mathrm{Ca} 2+$ channel activity in the endoplasmic reticulum. J Biol Chem 2008; 283: 15946-15955.

95. Xu C, Xu W, Palmer AE, Reed JC. Bl-1 regulates endoplasmic reticulum $\mathrm{Ca} 2+$ homeostasis downstream of Bcl-2 family proteins. J Biol Chem 2008; 283: 11477-11484.

96. Lee GH, Lee HY, Li B, Kim HR, Chae HJ. Bax inhibitor-1-mediated inhibition of mitochondrial $\mathrm{Ca} 2+$ intake regulates mitochondrial permeability transition pore opening and cell death. Sci Rep 2014; 4: 5194

97. Ahn T, Yun $\mathrm{CH}$, Kim HR, Cardiolipin Chae HJ. phosphatidylserine, and $\mathrm{BH} 4$ domain of $\mathrm{Bcl}-2$ family regulate $\mathrm{Ca} 2+/ \mathrm{H}+$ antiporter activity of human Bax inhibitor-1. Cell Calcium 2010; 47 : 387-396.

98. Senft D, UPR Ronai ZA. autophagy, and mitochondria crosstalk underlies the ER stress response. Trends Biochem Sci 2015; 40: 141-148.

99. Hetz C, Glimcher LH. Fine-tuning of the unfolded protein response: assembling the IRE1alpha interactome. Mol Cell 2009; 35: 551-561.

100. Rodriguez DA, Zamorano S, Lisbona F, Rojas-Rivera D, Urra H, Cubillos-Ruiz JR et al. $\mathrm{BH} 3-$ only proteins are part of a regulatory network that control the sustained signalling of the unfolded protein response sensor IRE1alpha. EMBO J 2012; 31: 2322-2335.

101. Chonghaile TN, Gupta S, John M, Szegezdi E, Logue SE, Samali A. BCL-2 modulates the unfolded protein response by enhancing splicing of X-box binding protein-1. Biochem Biophys Res Commun 2015; 466: 40-45.

102. Lee GH, Kim HK, Chae SW, Kim DS, Ha KC, Cuddy M et al. Bax inhibitor-1 regulates endoplasmic reticulum stress-associated reactive oxygen species and heme oxygenase-1 expression. J Biol Chem 2007; 282: 21618-21628.
103. Bailly-Maitre B, Belgardt BF, Jordan SD, Coornaert B, von Freyend MJ, Kleinridders A et al. Hepatic Bax inhibitor-1 inhibits IRE1alpha and protects from obesity-associated insulin resistance and glucose intolerance. J Biol Chem 2010; 285: 6198-6207.

104. Sica V, Galluzzi L, Bravo-San Pedro JM, Izzo V, Maiuri MC, Kroemer G. Organelle-specific initiation of autophagy. Mol Cell 2015; 59: 522-539.

105. Marino G, Niso-Santano M, Baehrecke EH, Kroemer G. Self-consumption: the interplay of autophagy and apoptosis. Nat Rev Mol Cell Biol 2014; 15: 81-94.

106. Oberstein A, Jeffrey PD, Shi Y. Crystal structure of the Bcl-XL-Beclin 1 peptide complex: Beclin 1 is a novel BH3-only protein. J Biol Chem 2007; 282: 13123-13132.

107. Pattingre S, Tassa A, Qu X, Garuti R, Liang XH, Mizushima N et al. Bcl-2 antiapoptotic proteins inhibit Beclin 1-dependent autophagy. Cell 2005; 122: 927-939.

108. Maiuri MC. Criollo A, Tasdemir E, Vicencio JM, Tajeddine N, Hickman JA et al. BH3-only proteins and $\mathrm{BH} 3$ mimetics induce autophagy by competitively disrupting the interaction between Beclin 1 and Bcl-2/Bcl-X(L). Autophagy 2007; 3: 374-376.

109. Maiuri MC, Le Toumelin G. Criollo A, Rain JC, Gautier F, Juin P et al. Functional and physical interaction between $\mathrm{Bcl}-\mathrm{X}(\mathrm{L})$ and a BH3-like domain in Beclin-1. EMBO J 2007; 26 2527-2539.

110. Ciechomska IA, Goemans GC, Skepper JN, Tolkovsky AM. Bcl-2 complexed with Beclin-1 maintains full anti-apoptotic function. Oncogene 2009; 28: 2128-2141.

111. Wei Y, Pattingre S, Sinha S, Bassik M, Levine B. JNK1-mediated phosphorylation of Bcl-2 regulates starvation-induced autophagy. Mol Cell 2008; 30: 678-688.

112. Wei $Y$, Sinha S, Levine B. Dual role of JNK1-mediated phosphorylation of Bcl-2 in autophagy and apoptosis regulation. Autophagy 2008; 4: 949-951.

113. Bellot G, Garcia-Medina R, Gounon P, Chiche J, Roux D, Pouyssegur J et al. Hypoxiainduced autophagy is mediated through hypoxia-inducible factor induction of BNIP3 and BNIP3L via their BH3 domains. Mol Cell Biol 2009; 29: 2570-2581.

114. Lindqvist LM, Heinlein M, Huang DC, Vaux DL. Prosurvival Bcl-2 family members affect autophagy only indirectly, by inhibiting Bax and Bak. Proc Natl Acad Sci USA 2014; 111 8512-8517.

115. Reljic B, Conos S, Lee EF, Garnier JM, Dong L, Lessene G et al. BAX-BAK1-independent $\mathrm{LC} 3 \mathrm{~B}$ lipidation by $\mathrm{BH} 3$ mimetics is unrelated to $\mathrm{BH} 3$ mimetic activity and has only minimal effects on autophagic flux. Autophagy 2016; 12: 1083-1093

116. Pedro JM, Wei Y, Sica V, Maiuri MC, Zou Z, Kroemer G et al. BAX and BAK1 are dispensable for ABT-737-induced dissociation of the BCL2-BECN1 complex and autophagy. Autophagy 2015; 11: 452-459.

117. Castillo K, Rojas-Rivera D, Lisbona F, Caballero B, Nassif M, Court FA et al. BAX inhibitor-1 regulates autophagy by controlling the IRE1alpha branch of the unfolded protein response. EMBO J 2011; 30: 4465-4478.

118. Sano R, Hou YC, Hedvat M, Correa RG, Shu CW, Krajewska M et al. Endoplasmic reticulum protein $\mathrm{Bl}-1$ regulates $\mathrm{Ca}(2)(+)$-mediated bioenergetics to promote autophagy. Genes Dev 2012; 26: 1041-1054.

119. Yadav RK, Lee GH, Lee HY, Li B, Jung HE, Rashid HO et al. TMBIM6 (transmembrane BAX inhibitor motif containing 6) enhances autophagy and reduces renal dysfunction in a cyclosporine A-induced nephrotoxicity model. Autophagy 2015; 11: 1760-1774.

120. Cardenas C, Miller RA, Smith I, Bui T, Molgo J, Muller M et al. Essential regulation of cell bioenergetics by constitutive InsP3 receptor Ca2+ transfer to mitochondria. Cell 2010; 142: 270-283. 